\title{
Spatial Distribution of Air Dose Rate in Grazing Grassland
}

\author{
Tamanna Islam*,1,2 and Mikinori Tsuiki ${ }^{1}$ \\ ${ }^{I}$ Faculty of Agriculture, Iwate University, Morioka, Japan \\ ${ }^{2}$ Department of Operations Management, American International University-Bangladesh, Dhaka, \\ Bangladesh
}

\begin{abstract}
A field study was carried out to determine the spatial distribution of air dose rate on grazed grassland after the earthquake on 11 March, 2011 in the Northwest Pacific of Northeastern Japan. Data on air dose rates $\left(\mu \mathrm{Sv} \mathrm{h}^{-1}\right)$ were collected from Ichinoseki, south of Iwate Prefecture, Japan. Air dose rates were collected from each of $1 \mathrm{~m}$ interval of $12 \times 12 \mathrm{~m}^{2}$ site (L-site). At the center of Lsite, $1.2 \times 1.2 \mathrm{~m}^{2}$ site (S-site) was located. One hundred and forty four (144) equal spaced quadrats were defined in the S-site. Again, air dose rates were collected from central point of each of the quadrat. Moran's I, a measure of autocorrelation was used to test the spatial heterogeneity of air dose rate on grazed grassland. Autocorrelation in S-site area was significantly higher than L-site area. Air dose rate did not show significant autocorrelation at any spatial lag in L-site. In S-site, air dose rate level showed significant autocorrelation in twelve of sixteen spatial lag. Autocorrelograms and Moran's scatterplot showed that air dose rate was frequently and positively spatially correlated at distance less than $0.1 \mathrm{~m}$.
\end{abstract}

Key words: Autocorrelation, Moran's I, Air dose rate

\section{Introduction}

On 11 March, 2011, a catastrophic earthquake and Tsunami occurred in the Northwest Pacific of Northeastern Japan. The magnitude of the earthquake was 9.0 (Kinoshita et al. 2011). The earthquake and Tsunami caused destruction in the Northeastern Japan and severely damaged the Fukushima Daiichi Nuclear Power Plant (NPP) (Yasunari et al. 2011). Fukushima and its adjacent prefectures were contaminated with nuclear fission products including ${ }^{129} \mathrm{mTe}$, ${ }^{131} \mathrm{I},{ }^{134} \mathrm{Cs},{ }^{136} \mathrm{Cs}$ and ${ }^{137} \mathrm{Cs}$ (Kinoshita et al. 2011). Nevertheless, areas away from Fukushima can be affected by high levels of depositions (MEXT 2011). Because, air parcel carried these radioactive elements and accumulate these elements on the ground by subsequent wet and dry depositions. Among these materials, radioactive ${ }^{137} \mathrm{Cs}$ and ${ }^{134} \mathrm{Cs}$ causes deleterious effect on agriculture and farming and then human life. Therefore, it causes the largest concerns in Japan.

After Chernobyl accident, it was found that radioactive cesium (Cs) contaminated air, water and soil particles over vast area of Europe (Cort et al. 1998). Radioactive Cs were carried with air and deposited in the top soil layer (Filipovic-Vincekovic et al. 1991). The top soil layer can remain these Cs for many years (Giani and Helmers 1997). Radioactive Cs also readily

${ }^{*}$ Corresponding author. 
absorbed by illitic clay minerals (Cremers et al. 1988). Radioactive Cs can easily be redistributed in grassland and agricultural soil. Plants take radionuclides from soil and radionuclides become available within food chains. In herbaceous vegetation nutrient uptake takes place in the first soil layer (Ehlken and Kirchner 1996). Therefore, there radionuclide concentration in the superficial soil layer is crucial for the soil-to-plant transfer process. Through food chains radionuclides in the environment can be passed onto human beings. As a result, create an environmental threat to the health of local population (Ciuffo et al. 2002, Howard et al. 1991). After Fukushima Daiichi nuclear disaster radioactive Cs was found in many grasslands in Iwate Prefecture (Tsuiki et al. 2011). The amount of radioactive materials fallout was greater in southern region of Iwate Prefecture than northern region (Tsuiki et al. 2011). In those grasslands, radioactive Cs level in grasses exceeded provisional safety standard for dairy and fattening cattle (MAFF 2011). As a result, livestock industries suffered serious damages namely disposal of polluted forages, prohibition of grazing, decline of beef price and shipping suspension, blanket test of beef cattle (Kurokawa and Sugimoto 2011). Therefore, it is necessary to study the spatial pattern of radioactive Cs on grassland in that area.

A number of researchers have conducted research on spatial distribution of radioactive Cs in more detail based on the collected sample after Chernobyl accident in 1986 (Luber et al. 2009). Using statistical approach spatial variation of contamination was discussed in these studies. Lognormal distribution was used to describe variation of ${ }^{137} \mathrm{Cs}$ contamination within "non-gradient" areas. Statistical approach also used to study spatial distribution pattern of chemical elements in soil (Sutherland 1996).

In this study, Moran's I was used to determine whether contaminated areas of air dose rate are clustered or not. To test for spatial autocorrelation for the air dose rate data Moran's I was used as an indicator of autocorrelation. In ecology Moran's I was used to determine the pattern of spatial autocorrelation as the analogous to Pearson's correlation coefficient. Positive value of Moran's I indicated positive spatial autocorrelation and negative value indicated negative spatial autocorrelation (Fortin and Dale 2005).

In the present study, the objective was to examine the spatial variation of air dose rate on the soil of grazed grassland. A comparison was also made to investigate the spatial pattern of air dose rate for two different time period.

\section{Materials and Methods}

\section{Source of Data}

The study area is situated at the Ichinoseki, south of Iwate Prefecture, Japan. Data were collected on 18 November, 2011 and 9 May, 2012. The study was based on sampling of air dose rates $\left(\mu \mathrm{Sv} \mathrm{h}^{-1}\right)$ from Orchardgrass (Dactylis glomerata L.) and Kentucky bluegrass (Poa pratensis L.) dominated grazed grassland. In the grassland, weeds (Artemisia indica var. maximowiczii and Rumex obtsuifolius L.) were frequently found. Data were collected using environmental radiation monitor (PA-1000 Radi, Horiba Ltd., Kyoto, Japan). As it is a typical pasture sites, a large variety of different herbaceous plants are growing at that site. The used site has been utilized for many years as grassland for grazing cows from June to November. 
In the study area the altitude is higher in Southwest side as compared to Northeast side. A $12 \times 12 \mathrm{~m}^{2}$ site (L-site) with grid lines at $1 \mathrm{~m}$ interval were laid out. On each of the grid line air dose rates were collected at each of the $1 \mathrm{~m}$ interval. Again $1.2 \times 1.2 \mathrm{~m}^{2}$ site (S-site) was located at the center of $12 \times 12 \mathrm{~m}^{2}$ site. $1.2 \times 1.2 \mathrm{~m}^{2}$ site was divided into $144(12 \times 12)$ equal spaced quadrats. From central point of each of the quadrat air dose rates were collected.

\section{Data Analysis}

Moran's I was used to evaluate spatial heterogeneity of air dose rate on grassland (Moran 1950; Huo et al. 2012). Let $x_{i}$ and $x_{j}$ represents the amount of air dose rate in $i$ th and $j$ th quadrat among $n$ quadrats, then the Moran's I can be defined as

$$
I=\frac{n}{(n-1) S^{2} W} \sum_{i=1}^{n} \sum_{j=1}^{n} w_{i j}\left(x_{i}-\bar{x}\right)\left(x_{j}-\bar{x}\right)
$$

where, $w_{i j}$ is the $i$ th and $j$ th element of the weighting matrix, $W=\sum_{i=1}^{n} \sum_{j=1}^{n} w_{i j}$ and $S^{2}$ is the variance of the observed air dose rates, can be calculated as,

$$
S^{2}=\frac{1}{(n-1)} \sum_{i=1}^{n}\left(x_{i}-\bar{x}\right)^{2}
$$

Moran's I was calculated for $n=144$. A spatial contiguity weight (e.g. rook contiguity) matrix was adopted in this study. In this case, the element of the $1^{\text {st }}$ row of the weighting matrix were $w_{11}=0, w_{12}=0.5, w_{13}=0, \ldots \ldots \ldots \ldots, w_{112}=0, w_{113}=0.5, w_{114}=0, \ldots \ldots \ldots . ., w_{1144}=0$. The element of the $2^{\text {nd }}$ row of the weighting matrix were $w_{21}=0.33, w_{22}=0, w_{23}=0.33, w_{24}=$ $0, \ldots \ldots \ldots \ldots, w_{213}=0, w_{214}=0.33, w_{215}=0, \ldots \ldots \ldots, w_{2144}=0$. By this way all others elements of the weighting matrix was defined, as $W=144$ can be found. The weighting matrix is as follows,

$$
w=\left[\begin{array}{cccccccccccccccccc}
0 & 0.5 & 0 & 0 & \ldots & 0 & 0.5 & 0 & 0 & \ldots & 0 & 0 & 0 & \ldots . & 0 & 0 & 0 \\
0.33 & 0 & 0.33 & 0 & \ldots & 0 & 0 & 0.33 & 0 & \ldots & 0 & 0 & 0 & \ldots . & 0 & 0 & 0 \\
\ldots & \ldots . & \ldots . & \ldots . & \ldots & \ldots . & \ldots & \ldots . & \ldots & \ldots . & \ldots . & \ldots . & \ldots & \ldots . & \ldots . & \ldots . \\
0 & 0 & 0 & 0 & \ldots & 0 & 0 & 0 & 0 & \ldots & 0 & 0.5 & 0 & \ldots & 0 & 0.5 & 0
\end{array}\right]_{144 \times 144}
$$

The values of Moran's I vary between -1 and 1. The large positive values represent the positive autocorrelation, values close to zero indicating absence of spatial autocorrelation and negative values represent the negative autocorrelation. 
Based on the formula $-1 /(n-1)$, Moran's I was used as index for heterogeneity. If the value of Moran's I is close to 0 then it refers to random pattern. If the value of Moran's I $>-1 /(n-1)$, the data showed clustering tendency. Again, for Moran's I $<-1 /(n-1)$ indicated regular pattern (Cral and Kuhn 2007).

\section{Results}

\section{Air Dose Rate}

Table 1 shows the mean of air dose rate in L-site area and S-site. For example, mean of air dose rate was 0.67 , together with the standard deviation (SD) 0.08 and coefficient of variation (CV) 12.1 for L-site, on 18 November, 2011. For S-site mean, SD and CV of air dose rate were $0.69,0.05$ and 7.2, respectively (Table 1).

For L-site, on 9 May, 2012, mean of air dose rate was 0.59, together with the SD 0.07 and CV 11.9. For S-site mean, SD and CV of air dose rate were $0.60,0.04$ and 6.7 , respectively (Table 1).

Table 1: Mean air dose rate with standard deviation and coefficient of variation for L-site and S-site

\begin{tabular}{ccccccc}
\hline $\begin{array}{c}\text { Sampling } \\
\text { date }\end{array}$ & L-site & \multicolumn{3}{c}{ S-site } \\
\hline & $\begin{array}{c}\text { Mean } \\
\left(\mu \mathrm{Sv} \mathrm{h}^{-1}\right)\end{array}$ & $\begin{array}{c}\text { SD } \\
\left(\mu \mathrm{Sv} \mathrm{h}^{-1}\right)\end{array}$ & $\mathrm{CV}$ & $\begin{array}{c}\text { Mean } \\
\left(\mu \mathrm{Sv} \mathrm{h}^{-1}\right)\end{array}$ & $\begin{array}{c}\text { SD } \\
\left(\mu \mathrm{Sv} \mathrm{h}^{-1}\right)\end{array}$ & $\mathrm{CV}$ \\
\hline 18 Nov. 2011 & 0.67 & 0.08 & 12.1 & 0.69 & 0.05 & 7.2 \\
9 May 2012 & 0.59 & 0.07 & 11.9 & 0.60 & 0.04 & 6.7 \\
\hline
\end{tabular}

SD, standard deviation; CV, coefficient of variation; Nov., November.

Analyzing mean of air dose rate it was found that on 18 November, 2011, mean is higher than that on 9 May, 2012 (Table 1). The main cause might be the decay of radioactive isotopes. With many radioactive isotope air doses include ${ }^{134} \mathrm{Cs}$ and ${ }^{137} \mathrm{Cs}$. The half-life of ${ }^{134} \mathrm{Cs}$ and ${ }^{137} \mathrm{Cs}$ is 2.06 and 30.17 year, respectively (Yasunari et al. 2011). Therefore, decay of ${ }^{134} \mathrm{Cs}$ and ${ }^{137} \mathrm{Cs}$ have an effect on the mean of air dose rate. Besides this, uneven fallout of air dose rate and redistribution by runoff and the presence of cattle dung, mean of air dose rate on 9 May, 2012, showed lower value than that on 18 November, 2012. Perk et al. (2002) showed that different amount of rainfall caused the occurrence of different patterns of erosion and deposition. With this pattern of erosion and deposition, intensity of overland flow and roughness of the soil surface, presence of cattle dung, snowfall and hills influence the spatial patterns of the air dose rate concentrations in the topsoil (Perk et al. 2002).

Spatial distribution pattern of air dose rate within the considered study area on 18 November, 2011, based on regular grid measurements has been represented in Figure 1a, b. In $\mathrm{S}$-site low values of air dose rate are surrounded by high values (Figure 1b). But for L-site we did not get these types of surroundings (Figure 1a). Here high and low air dose rate showed 
scattered pattern (Figure 1a). Similar results were found for the L-site and S-site on 9 May, 2012 (Figure 2a, b). 

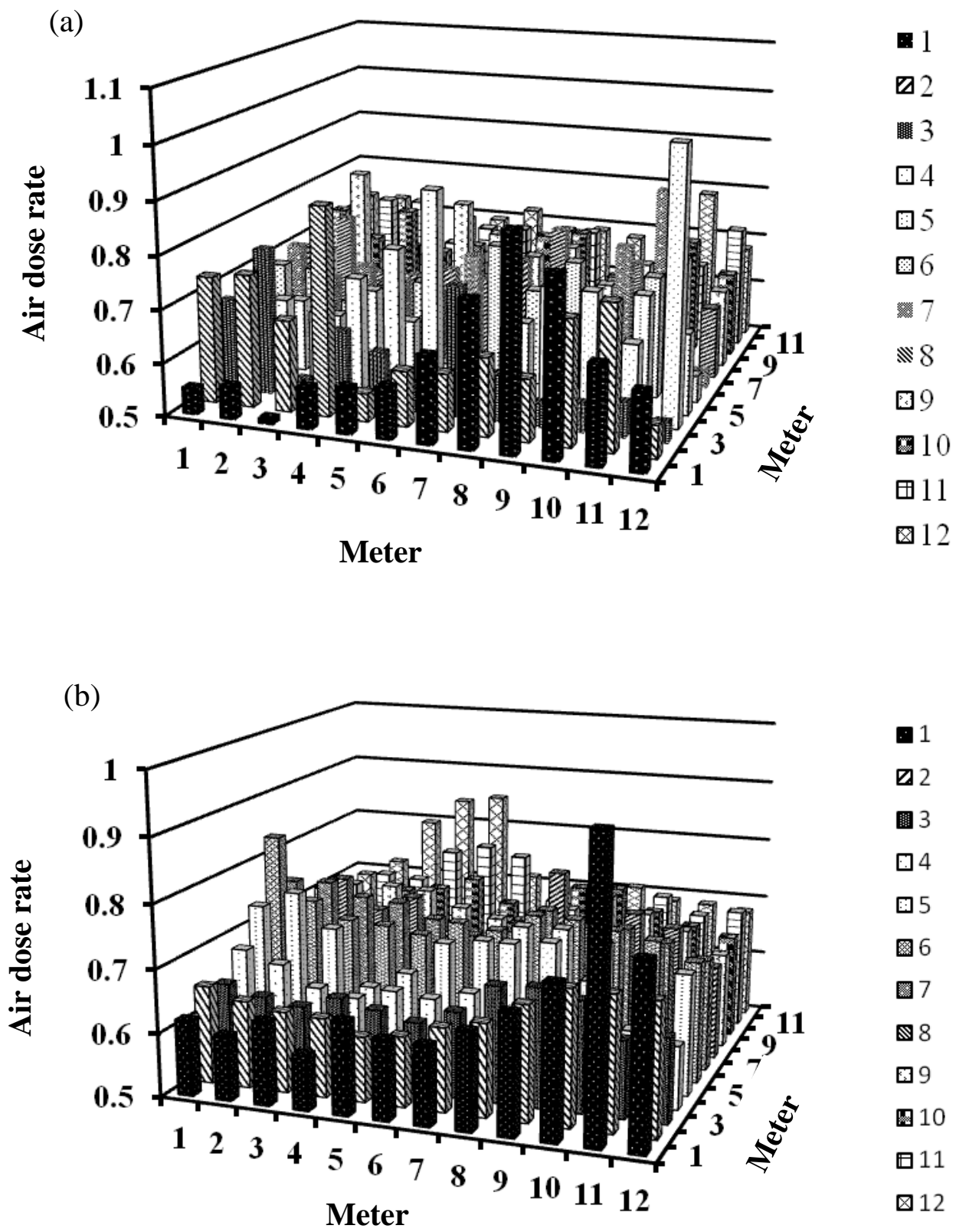

Figure 1: Spatial patterns of two areas of the air dose rate level in grassland community by 3D plot for (a) L-site and (b) S-site, on 18 November, 2011. Size of the area is given in meters 

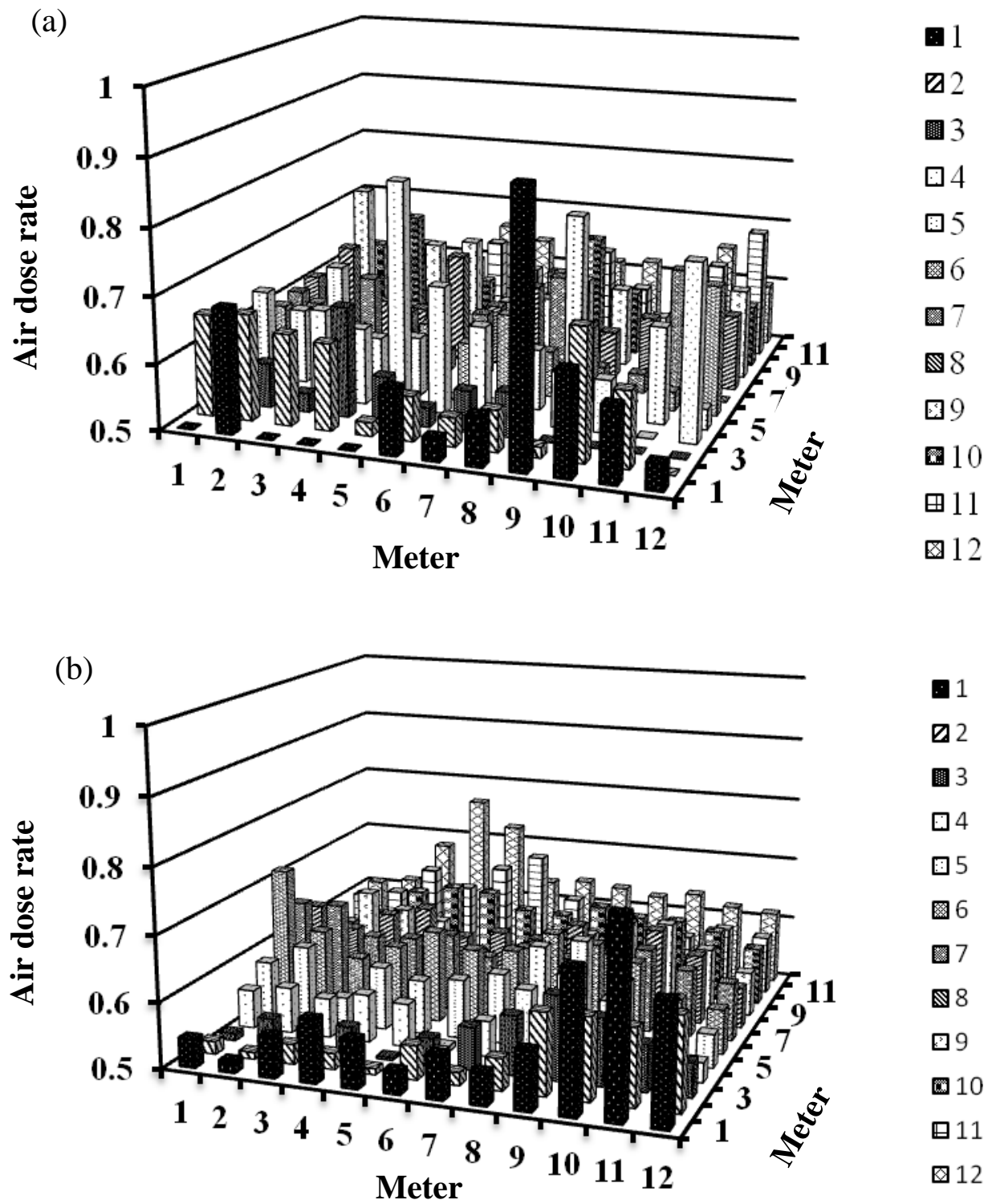

Figure 2: Spatial patterns of two areas of the air dose rate level in grassland community by 3D plot for (a) L-site and (b) S-site, on 9 May, 2012. Size of the area is given in meters 


\section{Autocorrelation}

Air dose rate data analyzed using Moran's I showed positive spatial autocorrelation for Lsite, on 18 November, 2011 (Table 2). This spatial autocorrelation is not significant ( $p$-value 0.1972) under the Moran's test.

For S-site area, on 18 November, 2011, Moran's I gave significant positive spatial autocorrelation (Table 2). The results described that clustering was strongest at shortest distance lag.

The Moran's I coefficient was significantly higher for S-site than L-site on 18 November, 2011 (Table 2). Values of Moran's I were greater than $-1 /(n-1)=-0.006$ indicating clustering tendency of the air dose rate.

Moran's I also showed positive spatial autocorrelation for L-site on 9 May, 2012 (Table 2). Under the Moran's test this value is not significant ( $p$-value 0.2422 ).

For S-site, on 9 May, 2012, Moran's I gave significant ( $p$-value <0.05) positive spatial autocorrelation (Table 2). The results described that at shortest distance air dose rate showed strong clustering tendency.

Also the Moran's I coefficient was significantly higher for S-site than L-site for 9 May, 2012 (Table 2). For S-site value of Moran's I was greater than $-1 /(n-1)=-0.006$. This result represented that in $\mathrm{S}$-site air dose rate showed clustering tendency.

Table 2: Moran's I for the two sample area on 18 November, 2011 and 9 May, 2012

\begin{tabular}{ccccc}
\hline Sampling date & \multicolumn{2}{c}{ L-site } & \multicolumn{2}{c}{ S-site } \\
\hline & Moran's I & $p$-value & Moran's I & $p$-value \\
\hline 18 Nov. 2011 & 0.044 & 0.1972 & 0.633 & $<0.05$ \\
9 May, 2012 & 0.035 & 0.2422 & 0.659 & $<0.05$
\end{tabular}

Nov., November; $p$-value of Moran's I test.

Autocorrelograms of air dose rate for L-site and S-site on 18 November, 2011, are given in Figure 3. Statistical significance of autocorrelation was tested at 5\% level assuming that correlation is zero. Autocorrelograms for L-site, showed positive autocorrelation at lag distance $1,3,4,5,6,7,8,9,13$ and 15 (Figure 3a). At lag distance 2,10,11,12,14 and 16 it showed negative autocorrelation (Figure 3a). But the autocorrelations are not significance at any lag distance. On the contrast, autocorrelogram for S-site, on 18 November, 2011, showed significant positive autocorrelation at lag distance from 1 to 6 , at lag distance 7 to 14 it showed negative autocorrelation and from 15 it again showed positive autocorrelation (Figure 3b). At all of the lag distance except 5, 6, 7 and 15 Moran's I values were significant at the conservative level of $p<0.05$. 


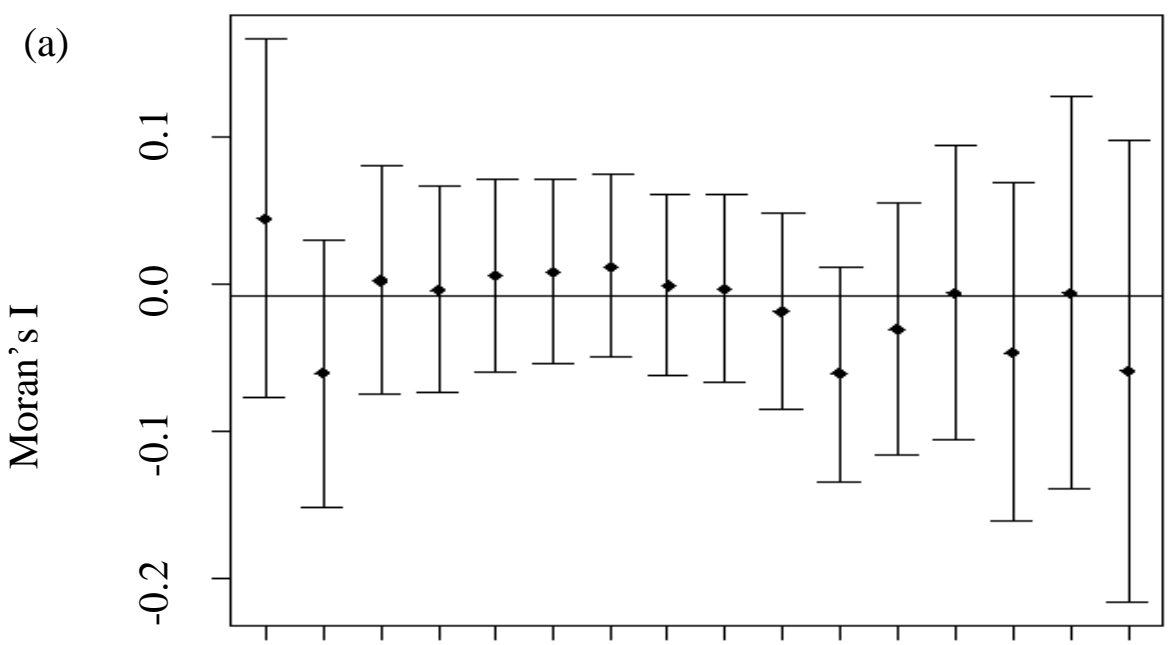

(b)

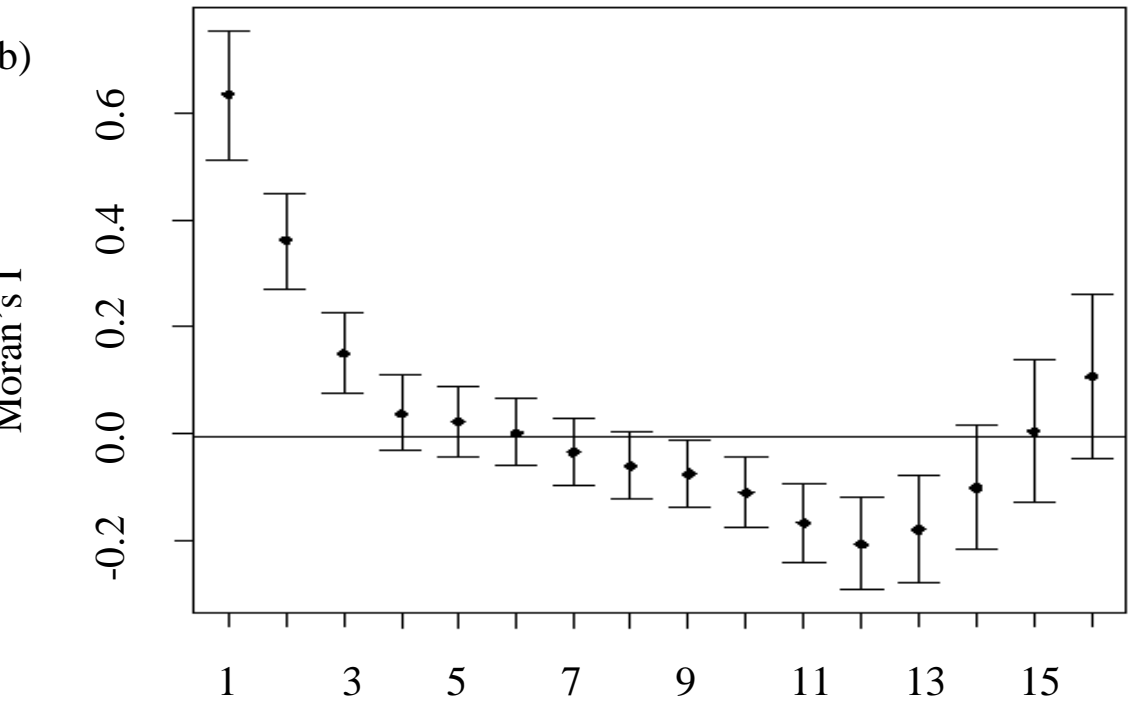

Lag distance

Figure 3: Autocorrelograms of two areas of the air dose rate level on grassland for (a) L-site and (b) S-site, on 18 November, 2011. All the points denote autocorrelation between successive quadrats to the used data sets

Figure 4a, b, represent the autocorrelograms for L-site and S-site on 9 May, 2012. For Lsite, autocorrelograms showed positive autocorrelation at lag distance 1, 2, 4, 5, 6, 7, 8 and 15 (Figure 4a). At lag distance 3, 9, 10, 11, 12, 13, 14 and 16 it showed negative autocorrelation (Figure 4a). At any lag distance they are not significance. On the other hand, autocorrelogram for S-site, showed significant positive autocorrelation at lag distance from 1 to 6 , at lag distance 
7 to 15 it showed negative autocorrelation and from 15 it again showed positive autocorrelation (Figure 4b). At all of the lag distance except 6, 7, 15 and 16 Moran's I values were significant at the conservative level of $p<0.05$.

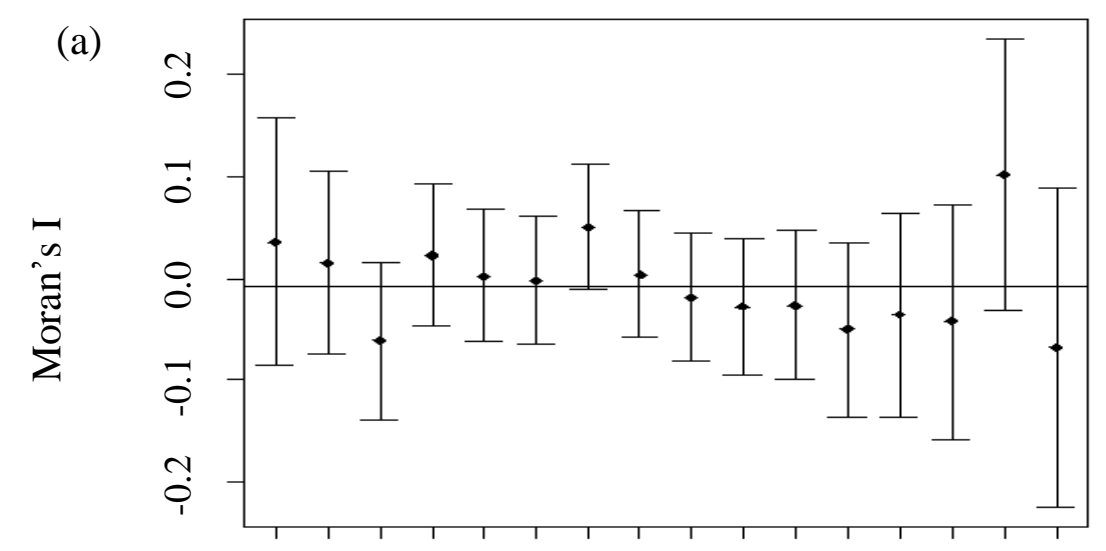

(b)

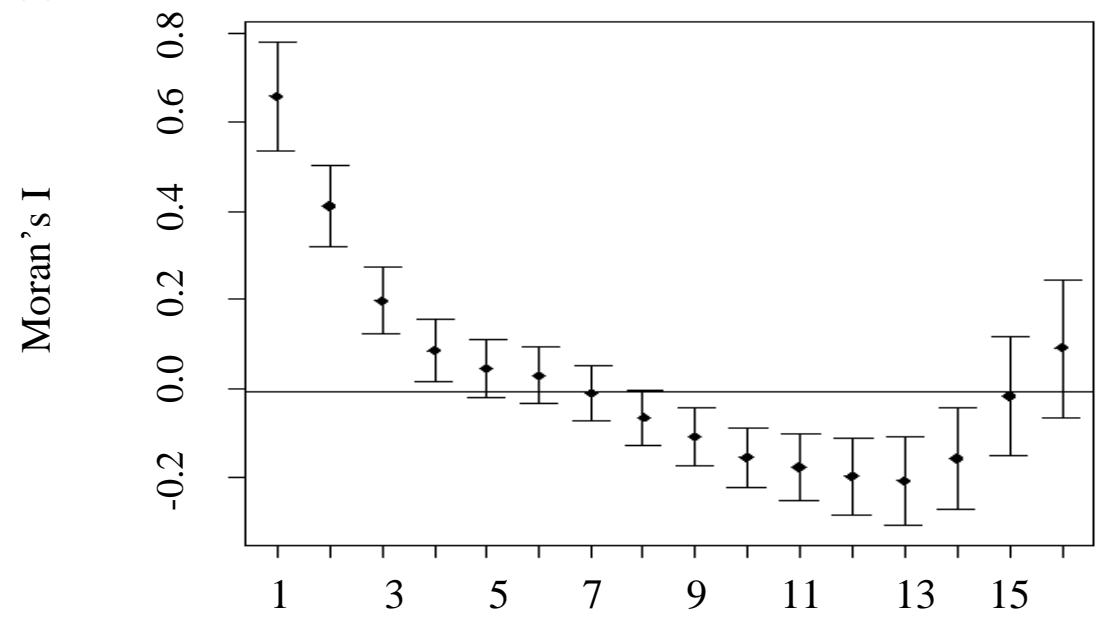

Lag distance

Figure 4: Autocorrelograms of two areas of the air dose rate level on grassland for (a) L-site and (b) S-site, on 9 May, 2012. All the points denote autocorrelation between successive quadrats to the used data sets 
Figure 5 shows Moran's scatter plot for the used data set on 18 November, 2011, with a fitted linear line. For the L-site, most of the values were centrally located and some of the values were scatteredly distributed (Figure 5a). Therefore, for L-site data did not show significant correlation (Figure 5a).

For the S-site, more than half of the values fall in the upper right quadrant (Figure 5b). So, these values showed high associations. There were two standout values. Rest of the values was fallen in the lower left quadrant (Figure 5b). These values showed positive spatial association. The overall tendency portrayed in the scatter plot is of positive correlation (Figure 5b).

Figure 6 illustrates Moran's scatter plot for air dose rate data set on 9 May, 2012. For the Lsite, most of the values were centrally located and some of the values were scatteredly distributed (Figure 6a). So, for L-site data did not show significant correlation (Figure 6a).

For the S-site, more than half of the values fall in the upper right quadrant and showed high associations (Figure 6b). Remaining values was fallen in the lower left quadrant. These values also showed positive spatial association. The overall tendency portrayed in the scatter plot is of positive correlation (Figure 6b). 

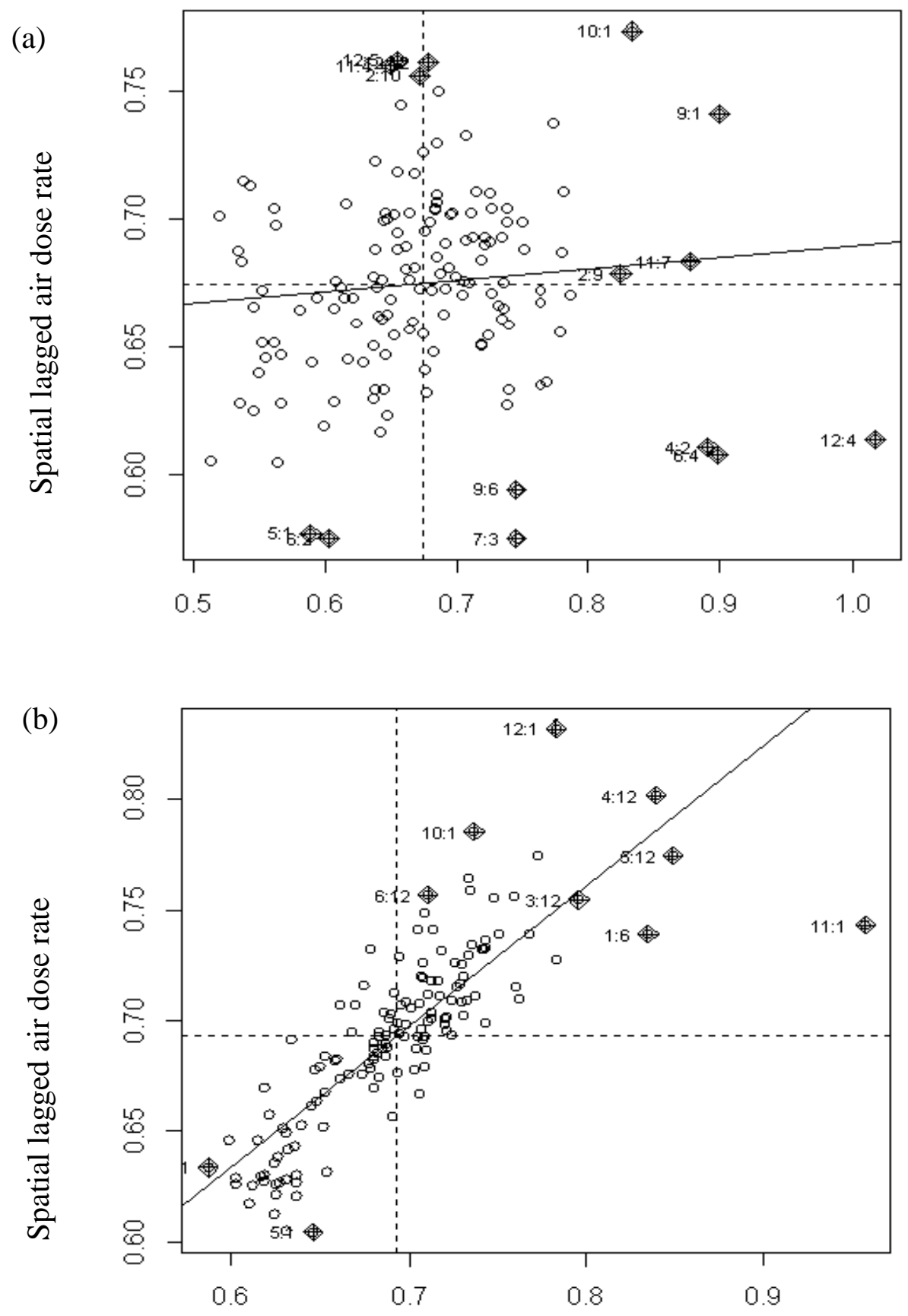

Air dose rate $\left(\mu \mathrm{Sv} \mathrm{h}^{-1}\right)$

Figure 5: Moran's scatter plot of two areas of the air dose rate level on grassland for (a) L-site and (b) S-site, on 18 November, 2011 
(a)

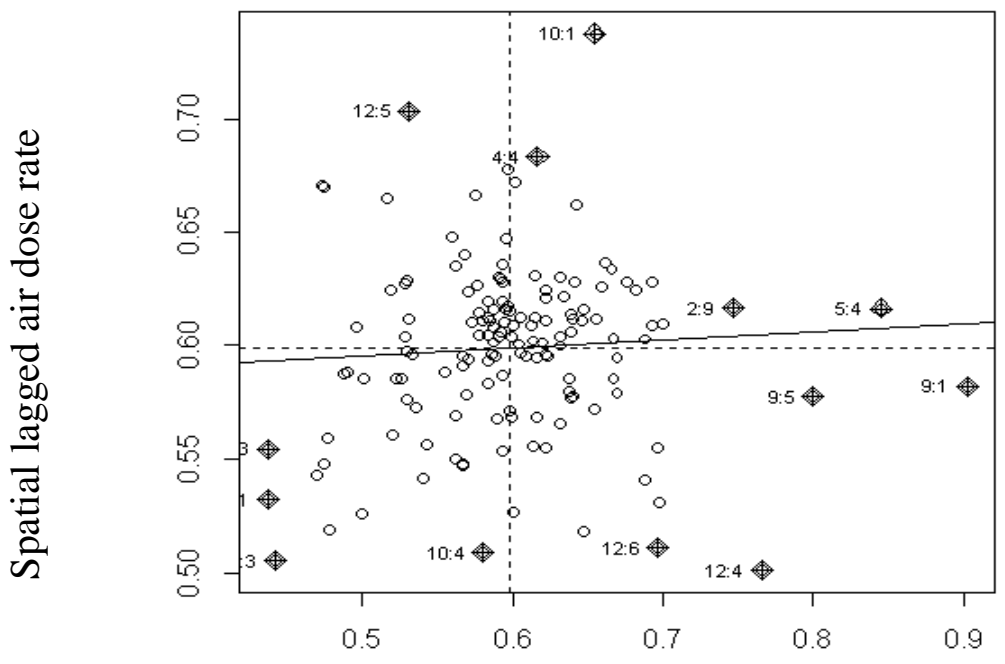

(b)

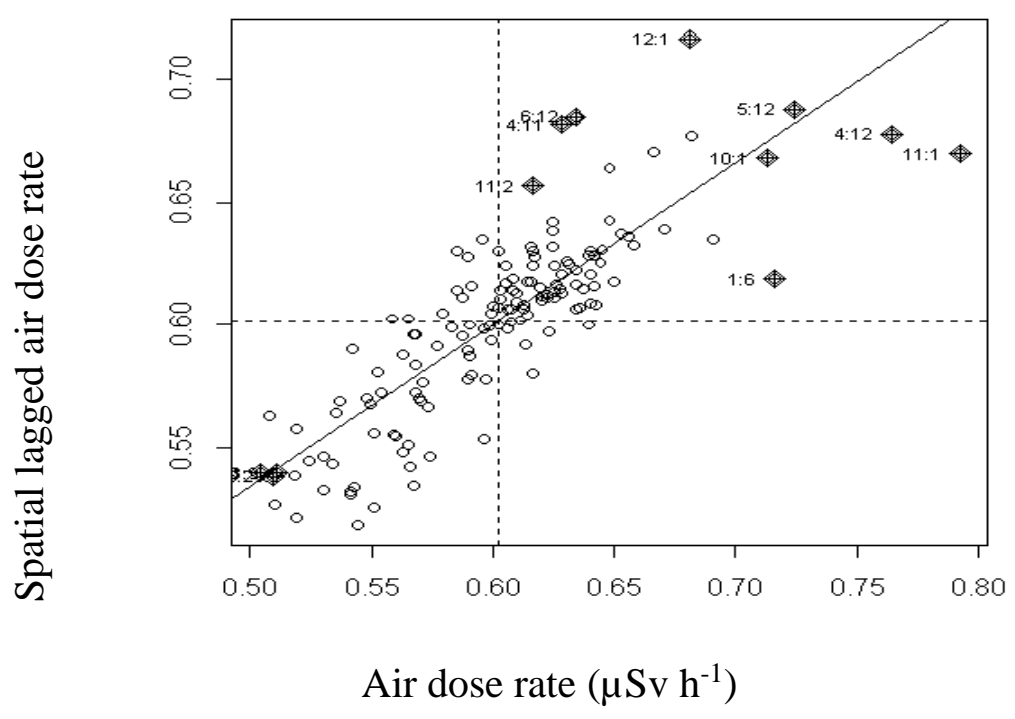

Figure 6: Moran's scatter plot of two areas of the air dose rate level on grassland for (a) L-site and (b) S-site, on 9 May, 2012

\section{Conclusions}

After Chernobyl accident many scientists used many methods to study the spatial pattern of radiation isotopes (Romanov and Korobova 2009). Perk et al. (2002) studied spatial variation of cesium-137 in small catchment. They suggest a redistribution model. Again mapping was used to test the non-random character of distribution of cesium-137 in space (Korobova and Romanov 2011). In this study Moran's I was used to described spatial pattern of air dose rate 
on grassland. The values of Moran's I for L-site were not significant under the Moran's I test (Table 2 and Figure 3a, 4a). On contrast, Moran's I gave significant result for S-site (Table 2). For S-site Moran's I showed high positive autocorrelation and showed that air dose rate tended to be heterogeneously distributed on the grassland community (Figure $3 b, 4 b$ ).

Moran's scatter plot reveals the spatial correlation between a point and its neighbor. Moran's scatter plot divides all points into four categories. Each of the categories is displayed in separate quadrants of the scatterplots as high:high (high radiation near high radiation values), high:low, low:high and low:low. In the scatter plot, the points are occurring in the upper right quadrant, identified clusters of high points. In this study, for the L-site most of the values were centrally located. So, data did not show significant autocorrelations (Figure 5a, 6a). Even as, for the $\mathrm{S}$-site data showed significant positive autocorrelation (Figure 5b, 6b).

In the L-site there were cattle dung, hills etc.. Therefore, with the distance of area cattle dung, hills, rainfall, snowfall etc. also had effect on the spatial heterogeneity of the air dose rate. Finally, it could be said that air dose rate was spatially heterogeneously distributed on the soil of grassland in the S-site area at distance less or equal to $0.1 \mathrm{~m}$.

\section{References}

[1] Carl, G. and Kuhn, I. (2007). Analyzing spatial autocorrelation in species distributions using Gaussian and logit models. Ecological Modelling 207, 159-170.

[2] Ciuffo, L. E. C., Belli, M., Pasquale, A., Menegon, S. and Velasco, H. R. (2002). 137Cs and $40 \mathrm{~K}$ soil-to-plant relationship in a seminatural grassland of the Giulia Alps, Italy. The Science of the Total Environment 295, 69-80.

[3] Cort, D., Dubois, M. G., Fridman, Sh. D., Germenchuk, M. G., Izrael, Yu. A., Janssens, A., Jones, A. R., Kelly, G. N., Kvasnikova, E. V., Matveenko, I. I., Nazarov, I. M., Pokumeiko, Y. M., Sitak, V. A., Stukin, E. D., Tabachny, L. Ya., Tsaturov, Y. S. and Avdyushin, S. I. (1998). Atlas of caesium deposition on Europe after the Chernobyl accident. Rep. EUR 16733. European Commission, Luxembourg.

[4] Cremers, A., Elsen, A. and Preter, P. D. (1988). Quantitative analysis of radio- cesium retention in soils. Nature 335, 247-249.

[5] Ehlken, S. and Kirchner, G. (1996). Seasonal variations in soil-to-grass transfer of fallout strontium and cesium and of potassium in north German soils. Journal of Environmental Radioactivity 33,147-181.

[6] Filipovic-Vincekovic, N., Barisic, D., Masic, N. and Lulic, S. (1991). Distribution of fallout radionuclides through soil surface layer. Journal of Radioanalytical and Nuclear Chemistry 148, 53-62.

[7] Fortin, M. J. and Dale, M. R. T. (2005). Spatial analysis: a guide for ecologists. Cambridge University Press, New York. 
[8] Giani, L. and Helmers, H. (1997). Migration of Cesium-137 in typical soils of North Germany ten years after the Chernobyl accident. Zeitschrift für Pflanzenernährung und Bodenkunde 160, 81-83.

[9] Howard, B. J., Beresford, N. A. and Hove, K. (1991). Transfer of radiocaesium to ruminants in natural and semi-natural ecosystems and appropriate countermeasures. Health Physics 61, $715-725$.

[10] Huo, X. N., Li, H., Sun, D. F., Zhou, L. D. and Li, B. G. (2012). Combining Geostatistics with Moran's I Analysis for Mapping Soil Heavy Metals in Beijing, China. International Journal of Environmental Research and Public Health 9, 995-1017.

[11] Kinoshita, N., Sueki, K., Sasa, K., Kitagawa, J. I., Ikarashi, S., Nishimura, T., Wong, Y. S., Satou, Y., Handa, K., Takahashi, T., Sato, M. and Yamagata, T. (2011). Assessment of individual radionuclide distributions from the Fukushima nuclear accident covering central-east Japan. Proceedings of the National Academy of Sciences of the United States of America (PANS) 108, 19526-19529.

[12] Korobova, E. and Romanov, S. (2011). Experience of mapping spatial structure of Cs-137 in natural landscape and patterns of its distribution in soil toposequence. Journal of Geochemical Exploration 109, 139-145.

[13] Kurokawa, A. and Sugimoto, T. (2011). A study on economic loss by shipping suspension of beef cattle derived from the Tohoku Earthquake. Journal of the Japanese Agricultural Systems Society 27 Extra issue 2, 27-28. (In Japanese).

[14] Luber, M., Tipaldi, G. D. and Arras, K. O. (2009). Spatially grounded multi-hypothesis tracking of people. Proceedings of the IEEE ICRA.

[15] MAFF. (2011). Survey results of radioactive material contents in grasses. Ministry of Agriculture, Forestry and Fishiries, Tokyo, available online: http://www.maff.go.jp/j/kanbo/joho/saigai/syouhi/bokusou_kensa.html (in Japanese)

[16] MEXT. (2011). Airborne monitoring survey by MEXT in Aichi, Aomori, Ishikawa, and Fukui prefectures. Ministry of Education, Culture, Sports, Science and Technology, Tokyo, available online:

http://radioactivity.mext.go.jp/en/contents/5000/4253/24/5000_1125e.pdf [cited 25 November, 2011]

[17] Moran, P. A. P. (1950). Notes on continuous stochastic phenomena. Biometrika 37, 17-23.

[18] Perk, M. V. D., Slavik, O. and Fulajtar, E. (2002). Assessment of spatial variation of cesium-137 in small catchments. Journal of Environmental Quality 31, 1930-1939. 
[19] Romanov, S. L. and Korobova, E. M. (2009). Geochemistry in space. Geochimica et Cosmochimica Acta Supplement 73, A1115.

[20] Sutherland, R. A. (1996). Cesium-137 soil sampling and inventory variability in reference locations: A literature survey. Hydrological Processes 10, 43-53.

[21] Tsuiki, M., Hinosawa, Y., Hatanaka, R., Kanno, S. and Maeda, T. (2011). The air dose rate map of Iwate Prefecture. Journal of the Japanese Agricultural Systems Society 27, 31-32 (in Japanese).

[22] Yasunari, J. T., Stohl, A., Hayano, S. R., Burkhart, F. J., Eckhardt, S. and Yasunari, T. (2011). Cesium-137 deposition and contamination of Japanese soils due to the Fukushima nuclear accident. Proceedings of the National Academy of Sciences 108, 19530-19534.

Received March 15, 2015; accepted November 10, 2015.

\author{
Tamanna Islam \\ Present Address \\ Department of Operations Management \\ American International University-Bangladesh \\ Dhaka 1213, Bangladesh. \\ E-mail: tamanna37@gmail.com \\ Work Place \\ Faculty of Agriculture, Iwate University \\ Morioka 020-8550, Japan. \\ E-mail: tamanna37@gmail.com \\ Mikinori Tsuiki \\ Faculty of Agriculture, Iwate University \\ Morioka 020-8550, Japan.
}

